\title{
Correction to: Lemborexant in insomnia disorder: a profile of its use
}

\author{
Hannah A. Blair ${ }^{1}$ \\ Published online: 1 October 2020 \\ (c) Springer Nature Switzerland AG 2020

\section{Corrections to: \\ Drugs \& Therapy Perspectives (2020) 36:427-434 https://doi.org/10.1007/s40267-020-00771-5}

The author has alerted us to the following errors, and the following corrections should be noted:

Page 431, 'What is the tolerability profile of lemborexant?' section, paragraph 2, lines 2-6: the following sentence, which previously read:

"Single and multiple doses of lemborexant $10 \mathrm{mg}$ did not have any negative effects on the apnea-hypopoea index (a measure of OSA severity) or peripheral capillary oxygen saturation (a measure of respiratory function)".

should read:

"Single and multiple doses of lemborexant $10 \mathrm{mg}$ did not have any negative effects on the apnea-hypopnea index (a measure of OSA severity) or peripheral capillary oxygen saturation (a measure of respiratory function)".

Page 433, reference list: Reference 12, which previously read:

12. Beuckmann CT, Ueno T, Nakagawa M, et al. Preclinical in vivo characterization of lemborexant (E2006), a novel dual orexin receptor antagonist for sleep/wake regulation. Sleep. 2019;42(6).

The original article can be found online at https://doi.org/10.1007/ s40267-020-00771-5.

Hannah A. Blair

demail@springer.com

1 Springer Nature, Private Bag 65901, Mairangi Bay, Auckland 0754, New Zealand should read:

12. Beuckmann CT, Ueno T, Nakagawa M, et al. Preclinical in vivo characterization of lemborexant (E2006), a novel dual orexin receptor antagonist for sleep/wake regulation. Sleep. 2019;42(6):zsz076.

Page 433, reference list: Reference 13, which previously read:

13. Mahoney CE, Mochizuki T, Scammell TE. Dual orexin receptor antagonists increase sleep and cataplexy in wild type mice. Sleep. 2019;43(6).

should read:

13. Mahoney CE, Mochizuki T, Scammell TE. Dual orexin receptor antagonists increase sleep and cataplexy in wild type mice. Sleep. 2019;43(6): $\underline{\text { zsz302. }}$.

Page 434, reference list: Reference 16, which previously read:

16. Moline M, et al. Effect of lemborexant compared with placebo and zolpidem extended release on sleep architecture in older adults with insomnia disorder [abstract]. Sleep Med. 2019;64(Suppl 1):s437.

should read:

16. Moline M, Pinner K, Cheng J, et al. Effect of lemborexant compared with placebo and zolpidem extended release on sleep architecture in older adults with insomnia disorder [abstract]. Sleep Med. 2019;64(Suppl 1):s437.

Page 434, reference list: Reference 29, which previously read:

29. Vermeeren A, Jongen S, Murphy P, et al. On-theroad driving performance the morning after bedtime 
administration of lemborexant in healthy adult and elderly volunteers. Sleep. 2019;42(4).

should read:

29. Vermeeren A, Jongen S, Murphy P, et al. On-theroad driving performance the morning after bedtime administration of lemborexant in healthy adult and elderly volunteers. Sleep. 2019;42(4):zsy260.

The original article has been updated. 